\title{
DOSADOR DE FERTILIZANTE COM DUPLA SAÍDA DESENVOLVIDO PARA AGRICULTURA FAMILIAR - AVALIAÇÃO DA VAZÃO MÁSSICA
}

\author{
César Augusto Azevedo Nogueira ${ }^{1}$ Ângelo Vieira dos Reis ${ }^{2}$, Márcia Beatriz Sila Vasconcelos ${ }^{3}$
}

\begin{abstract}
RESUMO
O objetivo deste trabalho foi determinar a influência da rotação do elemento dosador e da área de passagem de material sobre a vazão mássica de fertilizante sólido num dosador dotado de duas saídas de material, destinado ao uso em semeadoras-adubadoras de pequena capacidade. Para avaliar o funcionamento do dosador em laboratório, empregou-se o fertilizante NPK 05-20-20, caracterizado quanto ao teor de água, densidade aparente, granulometria e ângulo de repouso. O experimento foi planejado para avaliar o efeito conjunto da velocidade angular do rotor dosador de palhetas e da abertura de passagem de material do reservatório ao rotor dosador sobre a vazão mássica, num esquema fatorial $4 \times 4$, com cinco repetições por tratamento. Verificou-se que a vazão mássica do fertilizante empregado é diretamente proporcional à velocidade angular do rotor de palhetas do dosador de duas saídas e à área de abertura entre o reservatório e o rotor. Houve interação entre as variáveis. O mecanismo dosador desenvolvido foi capaz de dosar o material com razões de distribuição estimadas compatíveis com as práticas agrícolas.
\end{abstract}

Palavras-chave: razão de distribuição de adubo, adubação, semeadoras adubadoras

\section{ABSTRACT \\ FERTILIZER METER WITH DOUBLE OUTPUT DEVELOPED FOR FAMILY FARMING - ASSESSMENT OF THE MASS FLOW RATE}

The aim of this study was to establish the rotation influence of the meter component and the aperture of the hopper over the mass flow rate of solid fertilizer in a meter equipped with two outputs for dosed material, intended for use in small capacity planters. The meter was evaluated in laboratory using the fertilizer NPK 05-20-20, characterized according to water content, bulk density, particle size and repose angle. The experiment was designed to evaluate the combined effect of the angular speed of the rotor blades and the aperture of the hopper over the meter mass flow rate, in a factorial arrangement $4 \times 4$, with five replications. The mass flow of this fertilizer was found to be directly proportional to the angular speed of the two output meter rotors and to the aperture between the hopper and the rotor. There was interaction between the variables. The metering system developed was able to dispense the fertilizer with estimated distribution ratios compatible with agricultural practices.

Keywords: fertilizer distribution ratio, fertilizer, planter

\section{Recebido para publicação em 28/09/2016. Aprovado em 30/11/2016.}

1 - Engenheiro Mecânico, Professor do IFSul - Campus Pelotas, Curso de Mecânica, cesarnogueira@ifsul.edu.br.

2 - Engenheiro Agrícola, Professor Associado IV da UFPel/Pelotas-RS, Pesquisador do CNPq, areis@ufpel.edu.br.

3 - Engenheira Agrícola, Mestre em Ciências - UFPel, marciavasconcelos@gmail.com. 


\section{INTRODUÇÃO}

Segundo o Instituto Brasileiro de Geografia e Estatística (IBGE, 2006), a agricultura familiar é responsável por mais de $40 \%$ do valor bruto da produção agropecuária, representando $10,1 \%$ do Produto Interno Bruto (PIB) do pais, produzindo, em média, $60 \%$ do consumo interno, representando $84 \%$ dos imóveis rurais. Mesmo assim, existe terra ociosa devido à pouca mão de obra familiar disponível e ao baixo nível de mecanização das propriedades, não se consegue explorar toda a área, além de realizar as operações agrícolas na hora certa, com precisão e menos sofrimentos (ALVES, 2006).

Apesar da sua importância para a economia, a agricultura familiar, em sua maioria, carece de uma adequada oferta de tecnologias para desenvolvimento de suas atividades. Uma das opções para o aumento da produção e a redução do trabalho agrícola é a disponibilização e a adequação de máquinas, implementos e instalações, apropriados para as unidades familiares, uma vez que, tendo bases materiais diferenciadas, possuem também necessidades socioeconômicas e de manejo dos agroecossistemas distintas. Segundo Teixeira (2008), essa alternativa pela via tecnológica apresenta dificuldades: a indústria de máquinas agrícolas, de modo geral, provavelmente por questões mercadológicas, vem dedicando-se ao atendimento das necessidades dos médios e grandes estabelecimentos rurais, deixando uma lacuna no desenvolvimento de máquinas e implementos agrícolas voltados às pequenas propriedades.

Nota-se, portanto, uma carência, no mercado nacional, de máquinas e implementos agrícolas de baixa potência, que são justamente aqueles mais apropriados para o uso nas pequenas áreas mais comumente empregadas nas unidades familiares de produção. As semeadoras de baixa potência disponíveis hoje no mercado provêm, predominantemente, de fabricantes nacionais que dominam a tecnologia para a semeadura convencional ou direta em áreas grandes e médias. Decorre desse fato que a maioria das máquinas de pequeno porte disponibilizadas origina-se do projeto de máquinas maiores, o que gera inúmeras inadequações para o seu uso em pequenas áreas (NIEMCZEWSKI, 2014).

De acordo com Altmann et al. (2010), os principais fatores que influenciam no funcionamento dos mecanismos dosadores de fertilizantes são: inclinação de trabalho, velocidade de acionamento e o tipo de fertilizante.

Para resolver esse problema, é necessário que os projetos das máquinas agrícolas satisfaçam as necessidades dos pequenos agricultores. Com esse objetivo, Teixeira et al. (2009) avaliaram um dosador de sementes com duas saídas, parte integrante do projeto de uma semeadora utilizando um dosador para alimentar duas linhas. Da mesma forma, esse projeto, também exige apenas um dosador de fertilizante para as duas linhas de semeadura.

Vasconcelos (2011) desenvolveu o projeto conceitual, fabricou e testou o protótipo de um dosador de fertilizantes com dupla saída, o qual apresentou problemas oriundos, principalmente, da fabricação de seus elementos mecânicos.

No sentido de ampliar as possibilidades de projeto de semeadoras-adubadoras pelo emprego de novos princípios de solução, o presente trabalho tem o objetivo de determinar a influência da rotação do elemento dosador e da área de passagem de material sobre a vazão mássica de fertilizante sólido num dosador dotado de duas saídas de material dosado, construído por Vasconcelos (2011), verificando as razões de distribuição possíveis.

\section{MATERIAL E MÉTODOS}

Esse trabalho foi realizado nas instalações do laboratório do Núcleo de Inovação em Máquinas e Equipamentos Agrícolas da Universidade Federal de Pelotas (NIMEq/UFPel).

O protótipo do dosador de fertilizantes de dupla saída $^{4}$ foi fabricado em aço SAE 1020 (Figura 1).

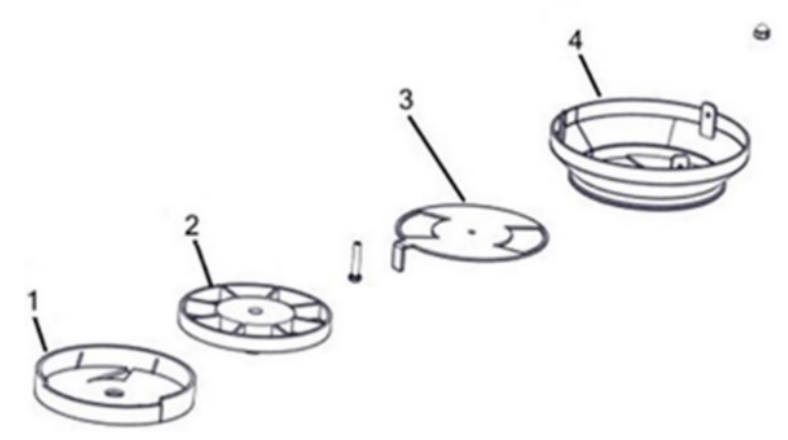

Figura 1. Vista em perspectiva explodida mostrando os componentes do dosador, onde: (1) fundo com as duas saídas; (2) rotor de palhetas; (3) comporta giratória; (4) base do reservatório.

4 - Universidade Federal de Pelotas. Patente requerida no INPI: BR1020120121573, em 22 de Maio de 2012. 
Para avaliação do protótipo do dosador foram realizados os ensaios: desempenho mecânico, determinação da influência da velocidade angular do rotor e da área de passagem de material sobre a vazão mássica de fertilizante, verificando as razões de distribuição possíveis. O dosador de dupla saída foi objeto de um depósito de patente, o qual é descrito como um mecanismo para a dosagem de material sólido na forma de pó ou particulado como fertilizantes químicos ou orgânicos, sementes ou corretivos de solo usados na agricultura, que apresenta duas saídas de material dosado, permitindo, assim, direcioná-lo, simultaneamente, às duas linhas de semeadura e garantindo a homogeneidade da distribuição longitudinal do material nas linhas.

Para realizar a dosagem do material, foi criado, como órgão ativo do dosador, um rotor dotado de palhetas (2), que gira no plano horizontal no fundo do reservatório (1) da máquina agrícola que contém o material. A passagem do material a ser dosado para o local onde se encontra o rotor de palhetas (2) é controlado por um sistema de comporta giratória (3), que pode interromper totalmente o fluxo do material para situações de manutenção do dosador. A rotação do rotor de palhetas (2) desloca, no volume compreendido entre duas palhetas consecutivas, o material que passou pela comporta giratória (3) até o local de saída do dosador, onde, pela ação da força da gravidade e do deslocamento contínuo da palheta, ele sai, através de um orifício de formato determinado, para o mecanismo de deposição constante na máquina agrícola onde for montado. Os orifícios de saída do material dosado, um para cada linha de semeadura, foram idealizados de forma que a borda que primeiramente entra em contato com o material conduzido pelo espaço entre as palhetas seja excêntrica em relação ao eixo de acionamento do rotor dosador, permitindo assim a deposição gradual desse material na linha da semeadura, sem oscilações e com regularidade de distribuição longitudinal.

Para avaliar o funcionamento do protótipo do dosador, foi utilizado um fertilizante comumente empregado pelos agricultores familiares, o NPK 05-20-20 mistura de grânulos. Também foram inseridas alterações no projeto mecânico de Vasconcelos (2011): no fundo com duas saídas foram inseridas ranhuras, na lateral interna, para facilitar a saída do fertilizante que ao longo do tempo pode acumular entre o rotor e a lateral interna e o eixo de acionamento do rotor de palhetas foi modificado para facilitar a sua montagem no elemento mecânico acionador do conjunto.

O acionamento mecânico do protótipo do dosador de fertilizantes, durante os ensaios de laboratório, se deu através de uma bancada dotada de um inversor de frequência que controla a rotação de um motor trifásico de $735 \mathrm{~W}$ continuamente na faixa entre 0 e $100 \mathrm{rpm}$ (Figura 2).

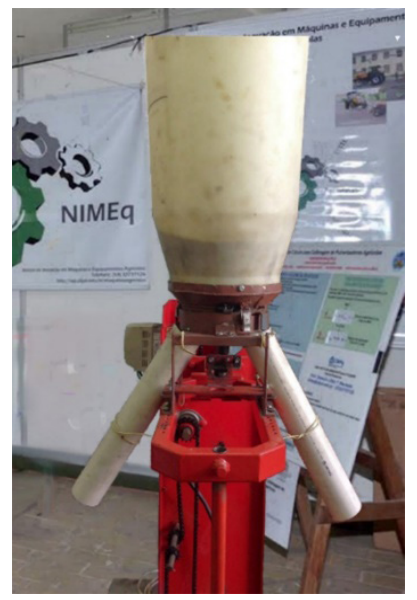

Figura 2. Vista geral da bancada de ensaio com o dosador montado.

Para a determinação das características físicas do fertilizante foram utilizados os materiais listado a seguir:

- ângulo de repouso - caixa com lateral envidraçada, máquina fotográfica com resolução de $10 \mathrm{Mpixel}$, funil e software CAD (Computer Aided Design) Solidworks ${ }^{\circledR}$;

- densidade - béquer de $1000 \mathrm{~mL}$ e balança analítica;

- granulometria - jogos de peneiras com orifícios de 1,$0 ; 2,0$; e 4,8 mm, agitador mecânico e balança analítica (resolução de $0,01 \mathrm{~g}$ );

- teor de água - estufa, dessecador e balança analítica (resolução de $0,01 \mathrm{~g}$ ).

As características físicas do fertilizante granulometria, densidade, teor de água e ângulo de repouso - foram obtidas a partir de amostras tomadas imediatamente antes dos ensaios de desempenho do dosador. 
A granulometria foi determinada pelo método das peneiras, divididas em grupos segundo a Instrução Normativa $n^{\circ} 03$, de 2015, do Ministério da Agricultura, Pecuária e Abastecimento.

$\mathrm{O}$ teor de água nos fertilizantes foi determinado segundo Alcarde et al. (1992), onde se retirou cinco amostras, que foram colocadas em almofariz e trituradas em um pilão até se tornarem pó, pesadas e, em seguida, colocadas em estufa a $50^{\circ} \mathrm{C}$ por um período de $24 \mathrm{~h}$. Após esse período, as amostras foram retiradas da estufa e pesadas. O teor de água presente no fertilizante utilizado foi determinado com a utilização da Equação (1):

$$
U=\left(\frac{m_{i}-m_{s}}{m_{s}}\right) \times 100
$$

em que:

$\mathrm{U}=$ teor de água do fertilizante em base seca (\%);

$\mathrm{mi}=$ massa inicial da amostra $(\mathrm{g})$; e

$\mathrm{ms}=$ massa da amostra seca $(\mathrm{g})$.

A densidade do fertilizante foi obtida utilizandose um béquer graduado de $1000 \mathrm{~mL}$. Através da pesagem de $1000 \mathrm{~mL}$ de fertilizante, em balança analítica, e a relação massa volume, obteve-se o valor pela média de três repetições.

$O$ ângulo de repouso do fertilizante foi determinado pela medição da inclinação formada pela superfície de deposição natural do produto. Para se obter o ângulo de repouso do material, foi utilizada uma estrutura de madeira, na forma de um quadro (tipo "aquário") composto por uma placa transparente (vidro), acoplando-se um funil na extremidade superior esquerda, por onde se adicionou o material com velocidade constante formando um amontoado suficiente para definir o ângulo de repouso. A medição do ângulo de repouso foi realizada através de fotografia digital obtida perpendicularmente à face envidraçada da caixa. Após esse procedimento, a fotografia foi importada pelo programa CAD (Computer Aided Design) Solidworks ${ }^{\circledR}$. Sobre a imagem, traçouse uma linha horizontal na base e uma linha acompanhado a superfície de repouso do material junto ao vidro. Com os recursos do programa, obteve-se o ângulo de repouso a partir de quatro repetições do experimento.
Neste dosador, há dois parâmetros que podem fazer variar a vazão mássica de fertilizante: a velocidade angular do rotor de palhetas e a regulagem da área de abertura de passagem de fertilizante do reservatório ao rotor. Dessa forma, o experimento foi planejado para avaliar o efeito conjunto desses dois parâmetros sobre a vazão mássica de fertilizante dosada por cada um dos orifícios de saída do dosador. Foram realizados ensaios utilizando o esquema fatorial $(4 \mathrm{x} 4)$, sendo avaliadas quatro regulagens da área de abertura do orifício de entrada de fertilizante no elemento dosador: abertura mínima (capaz de dosar de forma uniforme), duas aberturas intermediárias e a abertura total, respectivamente 290; 1800; 2900 e $3700 \mathrm{~mm}^{2}$ e quatro velocidades angulares do elemento dosador $(2,5 ; 5,0 ; 7,5$ e $10 \mathrm{rpm})$, com cinco repetições com duração de $30 \mathrm{~s}$ cada, totalizando, assim, 16 tratamentos e 80 unidades experimentais para cada saída. Após a estabilização da rotação do mecanismo, as amostras coletadas em cada saída, foram pesadas em balança digital e levantada a curva de vazão mássica do dosador abastecido com fertilizante NPK 05-20-20 mistura de grânulos.

Os resultados obtidos, para cada saída, foram submetidos a uma análise de variância ao nível de 5 e $1 \%$ de significância. As médias foram comparadas por meio do teste de Tukey, ao nível de $5 \%$ de significância, no caso da análise de variância ser significativa. As análises foram realizadas com o auxílio do programa Assistat versão 7.7 beta-2015 (SILVA e AZEVEDO, 2015).

\section{RESULTADOS E DISCUSSÃO}

As características físicas do fertilizante NPK 5-20-20 empregado nos ensaios são: densidade de 1,042 g.cm-3, ângulo de repouso de $33,00^{\circ}$ e teor de água de $4,18 \%$.

A granulometria do fertilizante utilizado nos ensaios encontra-se no Quadro 1.

Quadro 1. Granulometria do fertilizante utilizado nos ensaios.

\begin{tabular}{|c|c|}
\hline $\begin{array}{c}\text { Abertura da malha } \\
(\mathrm{mm})\end{array}$ & NPK 05-20-20 \\
\cline { 2 - 2 } & Massa retida $(\mathrm{g})$ \\
\hline 4,80 & 21,30 \\
\hline 2,00 & 417,30 \\
\hline 1,00 & 52,56 \\
\hline Fundo & 8,84 \\
\hline
\end{tabular}


A análise granulométrica do fertilizante utilizado mostra que a maior parte das partículas ficou retida entre as peneiras com 2 e $1 \mathrm{~mm}$ $(93,97 \%)$.

Os ensaios mostraram que as quantidades médias dosadas em cada saída foram estatisticamente iguais. Os resultados obtidos, para cada saída, foram submetidos a uma análise de variância ao nível de 5 e $1 \%$ de significância. As médias foram comparadas através do teste de Tukey, experimento inteiramente casualizado, ao nível de 5\%.

A análise de variância das médias de vazão mássica dos tratamentos de cada ensaio mostrou que, em todos os casos, elas foram afetadas significativamente, ao nível de $1 \%$ de probabilidade, pelos valores da abertura do reservatório e das rotações empregadas de forma conjunta, havendo interação entre esses fatores.

$\mathrm{O}$ Quadro 2 mostra o resultado do desdobramento da interação dos fatores velocidade angular e abertura do reservatório para a variável vazão mássica de fertilizante NPK 0520-10 mistura de grânulos, através de análise de variância ao nível de 5 e 1\% de significância. As médias formam comparadas através do teste de Tukey.

Analisando-se os resultados mostrados no Quadro 2, verifica-se que, para as aberturas estudadas, o fator velocidade, em seus níveis, causa efeito diretamente proporcional significativo na vazão mássica do dosador. Esse mesmo comportamento foi apresentado nos ensaios realizados com o protótipo do dosador de fertilizante desenvolvido por Vasconcelos (2011), quando foram testados 4 fertilizantes: NPK 05-2010, NR1 organo mineral ("bola preta"), pó de rocha e calcário.

O mesmo incremento significativo na vazão mássica pode ser observado, nas rotações $(5 ; 7,5$ e $10 \mathrm{rpm}$ ), quando a área de passagem do fertilizante aumenta de 290 para $1800 \mathrm{~mm}^{2}$. No entanto, aumentando a área de passagem para 2900 e 3700 $\mathrm{mm}^{2}$ a vazão se mantém praticamente inalterada, com apenas um pequeno decréscimo.

$\mathrm{Na}$ menor rotação $(2,5 \mathrm{rpm})$, isso somente pode ser observado quando a área de abertura passa de 1800 para $2900 \mathrm{~mm}^{2}$, mantendo-se constante na área de abertura total $\left(3700 \mathrm{~mm}^{2}\right)$. Acredita-se que isso se deva ao completo preenchimento do volume existente entre duas palhetas consecutivas do rotor pelo fertilizante já com área de abertura em 1800 $\mathrm{mm}^{2}$, indicando uma influência das características de fluxo deste fertilizante como o ângulo de repouso, teor de água e granulometria. Por meio da Figura 3, essas características podem ser mais bem compreendidas.

Quando se considera uma velocidade de operação de $5 \mathrm{~km} \cdot \mathrm{h}^{-1} \mathrm{e}$ o espaçamento de $1 \mathrm{~m}$ entre linhas, as vazões mássicas obtidas com dosador de palhetas representam razões de distribuição entre 63,6 e 303,4 kg.ha-1 do fertilizante NPK 05-20-20.

$\mathrm{O}$ aumento da vazão mássica de fertilizantes em função do incremento da rotação do órgão ativo do dosador é conhecido (Cappelli et al., 2000; Ferreira et al., 2010) e, nos casos dos dosadores helicoidais, a vazão pode ser modelada por parâmetros físicos do material, dimensões e velocidade angular

Quadro 2. Médias da vazão mássica de fertilizante NPK dentro dos níveis dos fatores velocidade angular e área de abertura do orifício.

\begin{tabular}{|c|c|c|c|c|}
\hline \multirow{2}{*}{ Velocidade Angular (rpm) } & \multicolumn{4}{|c|}{ Área de abertura $\left(\mathrm{mm}^{2}\right)$} \\
\cline { 2 - 5 } & 290 & 1800 & 2900 & 3700 \\
\cline { 2 - 5 } & ----------------- \\
\hline 2,5 & $17,67 \mathrm{aA}$ & $20,84 \mathrm{aB}$ & $25,25 \mathrm{aC}$ & $24,85 \mathrm{aC}$ \\
\hline 5,0 & $28,05 \mathrm{bA}$ & $43,75 \mathrm{bB}$ & $36,12 \mathrm{bC}$ & $36,43 \mathrm{bC}$ \\
\hline 7,5 & $31,44 \mathrm{cA}$ & $63,28 \mathrm{cB}$ & $54,76 \mathrm{cC}$ & $54,44 \mathrm{cC}$ \\
\hline 10,0 & $34,68 \mathrm{dA}$ & $84,37 \mathrm{~dB}$ & $74,46 \mathrm{dC}$ & $74,84 \mathrm{dC}$ \\
\hline
\end{tabular}

Médias seguidas pela mesma letra minúscula dentro da coluna e de letras maiúsculas dentro da linha não diferem estatisticamente entre si ao nível de significância de $5 \%$ pelo teste de Tukey. DMS $=0,49$ g.s $\mathrm{s}^{-1}$ 

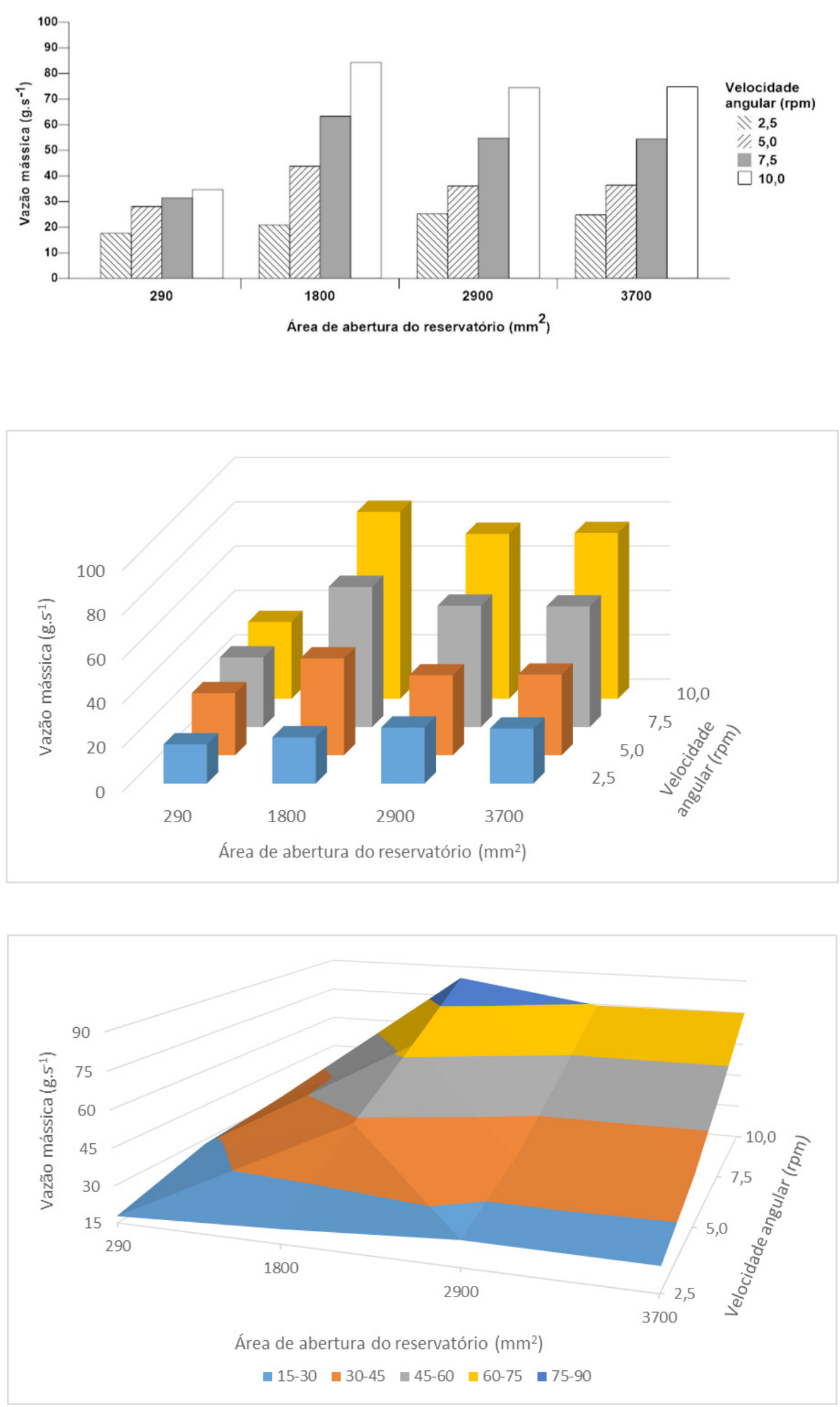

Figura 3. Variação da vazão mássica de fertilizante NPK 05-20-10 mistura de grânulos em função da área de abertura do reservatório e da velocidade angular do rotor.

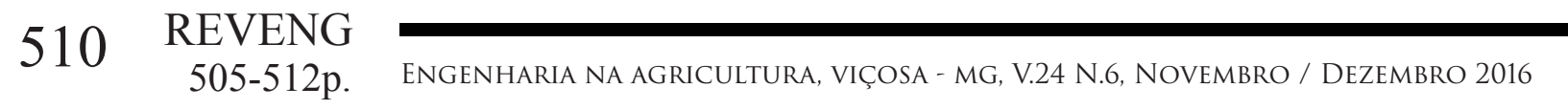


do helicóide. A equação do modelo pode ser empregada em processos de controle automático da vazão do dosador em agricultura de precisão (Garcia et al., 2012). Essa relação diretamente proporcional entre rotação do órgão ativo e vazão mássica também foi observada, como esperado, no presente dosador para o fertilizante ensaiado.

Camacho-Tamayo et al. (2009) ensaiaram quatro tipos de dosadores de fertilizantes, entre eles um dosador do tipo roseta, o qual apresenta alguma similaridade com o mecanismo ora apresentado, pois também transfere o material que se aloja entre os dentes da roseta até um orifício de saída. Segundo os autores, esse mecanismo se adapta à aplicação de fertilizantes em altas razões de distribuição. A vazão mássica produzida pelo dosador tipo roseta foi diretamente proporcional à velocidade angular de seu eixo para todos os fertilizantes empregados (calcário, gesso, NPK e ureia), da mesma forma como o observado neste trabalho.

A influência da área de abertura entre o reservatório e o rotor de palhetas, outro parâmetro estudado nesse trabalho, sobre a vazão mássica de fertilizante não foi diretamente proporcional para os tratamentos estudados.

Luz et al. (2010) e Molin et al. (2009) afirmam que as características físicas dos fertilizantes influenciam o desempenho de seus dosadores. Sendo assim, o comportamento divergente no produto dosado, NPK 05-20-20, deve-se às suas características físicas, tais como: ângulo de repouso, densidade, teor de água e granulometria. Essas mesmas características, juntamente com a velocidade angular do elemento ativo, foram empregadas por Camacho-Tamayo et al. (2009) para construir modelos de regressão linear que explicaram a vazão mássica de quatro tipos de dosadores.

\section{CONCLUSÕES}

- A vazão mássica do fertilizante empregado é diretamente proporcional à velocidade angular do rotor de palhetas do dosador de duas saídas.

- Houve interação entre as variáveis velocidade angular do rotor de palhetas e área de abertura entre o reservatório e o elemento dosador.

- O protótipo do dosador de fertilizante de dupla saída desenvolvido foi capaz de dosar o fertilizante NPK 05-20-20 com razões de distribuição estimadas compatíveis com as práticas agrícolas.

\section{REFERÊNCIAS BIBLIOGRÁFICAS}

ALCARDE, J.C. et al. Avaliação da higroscopicidade de fertilizantes e corretivos. Scientia Agricola, Piracicaba, v. 49, n. spe, p. 137-144, 1992. Disponível em: http://www.scielo. $\mathrm{br} / \mathrm{scielo}$.php? script $=$ sci_arttext\&pid $=\mathrm{S} 0103$ $90161992000400018 \& \operatorname{lng}=$ en\&nrm=iso. Acesso em: 12 jan. 2015.

ALTMANN, A.S.; BONOTTO, G.J.; BEDIN, P.R.; SILVEIRA, H.A.T.; CARPES, D.P.; DIAS, V.O.; MONTEMEZZO J.; ALONÇO, A.S. Metodologia para avaliação dos mecanismos dosadores de fertilizantes em semeadoras-adubadoras. In: Simpósio de Ensino, Pesquisa E Extensão, 14. 2010, Santa Maria, RS. Simpósio de Ensino, Pesquisa e Extensão - SEPE. Santa Maria, RS: Centro Universitário Franciscano, 2010. 16-17p.

ALVES, E. Carta da Agricultura. Revista de Política Agrícola, n.4, p.3, 2006. Disponível em: http:// www.agricultura.gov.br/arq_editor/Revista $\% 20$ 4\%2006.pdf. Acesso em: 15 dez. 2014.

BRASIL. Ministério da Agricultura, Pecuária e Abastecimento. Instrução Normativa n.3, 2015. Métodos oficiais para realização de ensaios em amostras oriundas do controle oficial de fertilizantes e corretivos Disponível em: http://sistemasweb. agricultura.gov.br/sislegis/action/detalhaAto.do?m ethod $=$ consultarLegislacaoFederal Acesso em: 03 mar. 2015.

BRASIL. Ministério da Agricultura, Pecuária e Abastecimento. Manual de métodos analíticos oficiais para fertilizantes minerais, orgânicos, organominerais e corretivos / Ministério da Agricultura, Pecuária e Abastecimento. Secretaria de Defesa Agropecuária. Coordenação-Geral de Apoio Laboratorial; Murilo Carlos Muniz Veras 
(Org.) - Brasília: MAPA/SDA/CGAL, 2014. Disponível em: http://www.agricultura.gov.br/ arq_editor/file/Laboratorio/manual1\%20_ in $\% 20$ 5_\%20analiticos-oficiais-para-fertilizantes-ecorretivos_com_capa_final_03.pdf Acesso em: 10 jan. 2015.

CAMACHO-TAMAYO, Jesus H. et al. Operational characteristics of four metering systems for agricultural fertilizers and amendments. Engenharia. Agrícola, v.29, n.4, p.605-613, 2009. Disponível em: http://dx.doi.org/10.1590/S010069162009000400010. Acesso em 12 jul. 2012.

CAPPELLI, N.L.; UMEZU, C.K.; MARTINS, M.M. Avaliação do desempenho de um dosador helicoidal para aplicação de fertilizantes sólidos. Engenharia Agrícola, v.20, n.2, p.130-138, 2000.

CENSO AGROPECUÁRIO 2006. Disponível em: www.ibge.gov.br/home/estatistica/economia/ agropecuaria/censoagro/agri_familiar_2006/ familia_censoagro2006.pdf. Acesso em: 23 jul. 2014.

FERREIRA, M.F.; DIAS, V.O.; OLIVEIRA, A.; ALONÇO, A.S.; BAUMHARDT, U.B. Uniformidade de vazão de fertilizantes por dosadores helicoidais em função do nivelamento longitudinal. Engenharia na Agricultura, v.18, p.297-304, 2010.

GARCIA, A.P.; CAPPELLI, N.L.; UMEZU, C.K. Auger-type granular fertylizer distributor: matemathical model and dynamic simulation. Engenharia Agrícola, v.32, n.1, p.151-163, 2012.

LUZ, P.H.C.; OTTO, R., VITTI, G.C., QUINTINO, T.A., ALTRAN, W. S., IKEDA, R. Otimização da aplicação de corretivos agrícolas e fertilizantes. Informações Agronômicas. n.129, mar 2010. Disponível em: http://www.ipni.net/ PUBLICATION/IA-BRASIL.NSF/0/909E88E68 F51B54883257A90000D5EE0/\$FILE/Page1-13129.pdf Acessado em: 15 fev. 2014.
MOLIN, J.P.; MACHADO, T.M., MAGALHÃES, R.P., FAULIN, G.D.C. Segregação de fertilizantes aplicados a lanço. Engenharia Agrícola, v.29, n.4, p.614-622, out./dez, 2009.

NIEMCZEWSKI, Bóris K. et al. Validação de um modelo de cálculo por elementos finitos do chassi de uma semeadora de quatro linhas. Revista Engenharia Agrícola, Jaboticabal, v. 34, n. 1, p. 161-170, Fev. 2014. Disponível em: <http:// dx.doi.org/10.1590/S0100-69162014000100017 >. Acesso em: 24 maio 2014.

SILVA, F.A.S.; AZEVEDO, C.A.V. Versão 7.7 do programa computacional Assistat. Disponível em: $<$ http://www.assistat.com>. Acesso em: 20 Jun. 2015.

TEIXEIRA, S.S. Projeto Conceitual de Uma Semeadora de Milho e Feijão Voltada para a Agricultura Familiar de Base Ecológica. 2008. 113p. Dissertação (Mestrado em Ciências). Universidade Federal de Pelotas, Pelotas.

TEIXEIRA, S.S.; REIS, A.V.; MACHADO, A.L.T.; BISOGNIN, A.; SILVEIRA, H.A.T. Distribuição longitudinal de sementes de milho com dosador de disco horizontal operando com uma ou duas saídas de sementes. Ciência Rural, v.39, p.241721, 2009a.

UNIVERSIDADE FEDERAL DE PELOTAS. Silvia Trisch dos Santos Acunha. Dosador de palhetas com duas saídas de material. BR 10 20120121573 A8, 22 maio 2012. Disponível em: https://gru.inpi.gov.br/pePI/servlet/PatenteServlet Controller?Action $=$ detail $\&$ CodPedido $=912133 \&$ SearchParameter $=$ BR1020120121573 Acesso em: 30 jan. 2015.

VASCONCELOS, M.B.S. Desenvolvimento de um dosador de fertilizantes com dupla saída. 2011. Dissertação (Mestrado em Ciências). Universidade Federal de Pelotas, Pelotas. 